\title{
Retour sur« La Formule de Mauss »
}

\section{François Sigaut}

\section{OpenEdition}

Journals

Édition électronique

URL : https://journals.openedition.org/tc/5214

DOI : $10.4000 /$ tc. 5214

ISSN : 1952-420X

\section{Éditeur}

Éditions de l'EHESS

\section{Édition imprimée}

Date de publication : 30 juin 2010

Pagination : 354-356

ISSN : 0248-6016

\section{Référence électronique}

François Sigaut, «Retour sur « La Formule de Mauss »», Techniques \& Culture [En ligne], 54-55 | 2010, mis en ligne le 30 janvier 2013, consulté le 29 septembre 2022. URL : http://journals.openedition.org/ tc/5214 ; DOI : https://doi.org/10.4000/tc.5214 


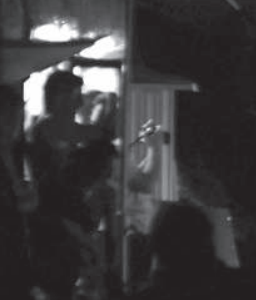

$$
\text { * roy }
$$




\section{Retour sur}

\section{«La Formule de Mauss »}

Cet article comporte deux parties assez différentes. La première est une réflexion d'ordre général sur la nature des faits sociaux et culturels. La seconde est un essai pour explorer les implications de la célèbre définition de la technique proposée par Mauss en 1934: l'action traditionnelle efficace.

En réalité, et bien que je n'en aie peut-être pas assez explicité les raisons, ces deux parties représentent les deux aspects d'une même question: les faits techniques sont-ils des faits sociaux? Pour nous à Techniques \& culture, cela va de soi. Mais pour la plupart de nos collègues historiens, sociologues, etc., cela ne va de soi qu'en apparence, pas en réalité, et c'est cette réalité négative que j’avais en tête en écrivant. Il ne suffit pas d'affirmer que les faits techniques sont des faits sociaux, il faut le démontrer, ou plus exactement il faut nous efforcer de faire tomber les préventions que nos collègues entretiennent implicitement à l'encontre de cette idée - toute la difficulté étant dans l'« implicitement ».

Les faits techniques sont-ils des faits sociaux? Cela dépend évidemment de la conception qu'on se fait des uns et des autres. Or si Mauss nous donne une excellente définition des faits techniques, nous n'avons pas l'équivalent pour les faits sociaux. Ou pour mieux dire, nous en avons trop, et de trop différentes, ce qui laisse subsister toutes les incertitudes. Ce sont ces incertitudes qui, dans les « conversations de couloir», laissent libre cours à l'idée que la technique et le social sont choses sans rapports entre elles. Mais comme ces conversations ne laissent pas de traces, il est bon d'en trouver la substance dans les écrits de quelques auteurs moins prudents ou plus naifs que les autres. C'est pourquoi j'ai cité Poirier. Mais il n'est pas le seul à avoir pensé que « l'univers du rationnel échappe à l'anthropologie ». Voltaire, Auguste Comte, Durkheim, Alain, Lévi-Strauss ont dit chacun à leur façon à peu près la même chose, je les ai cités dans mon introduction à La Technologie science humaine, d'A.-G. Haudricourt (1987 : 14-16). 
Je voudrais profiter de l'occasion qui m'est offerte ici pour ajouter deux noms à cette liste: Bouglé et Halbwachs. Dans « Matière et société » article paru en 1920, Halbwachs explique que du fait que son travail le met en dialogue direct avec la matière, l'ouvrier au travail sort de la société, qu'il ne réintègre que lorsqu'il retrouve sa famille ou ses amis pour d'autres activités, qui ne sont plus techniques. Et dans « L'Origine de la technique positive » (1922), Célestin Bouglé soutient l'idée que les techniques auraient d'abord été des rites. Car les rites, eux, sont des faits sociaux puisque collectifs. Il suffit d'imaginer que de temps en temps, le hasard fait qu'il y a un rite qui marche, et vous avez une technique. Si par exemple vous offrez des aliments à l'esprit d'un mort en jetant des graines sur sa tombe, et si ces graines germent, vous aurez inventé l'agriculture!

Je n'exagère pas. Cet exemple figure en toutes lettres dans l'article de Celestin Bouglé. Et ce n'est pas pour le plaisir de la caricature que je le cite (encore que toutes les occasions de s'amuser soient bonnes à prendre), mais parce qu'il faut avoir conscience que ce genre de théories a été pris tout à fait au sérieux à une certaine époque. Mauss n’a pas fait exception: la relecture de son Esquisse d’une théorie générale de la magie (1902-1903) ne laisse aucun doute sur ce point, et dans Les Civilisations, éléments et formes (1930), il reprend encore l'idée que « tout phénomène social est [...] arbitraire ». On ne peut qu'en admirer davantage la reconversion opérée avec « Les Techniques du corps » (1936), confirmée dans le Manuel d'ethnographie (1947).

Dans le Manuel, justement, Mauss affirme haut et fort que la technique ne doit pas être réduite à l'économie. C'est un point essentiel, et il est clair que l'économisme, ou l'utilitarisme pour employer un terme plus général, est une approche tout à fait stérilisante du fait technique. C'est pourquoi le jeu, qui tend à rétablir l'équilibre, est une perspective si importante pour comprendre les faits techniques - et les faits sociaux.

Ce qui me conduit à une dernière remarque. Un des auteurs qui ont le mieux parlé du jeu et des jeux a été Roger Caillois. Pourquoi ne l'ai-je pas cité dans mon article, alors que je connaissais et que j'admirais son ouvre? Je suis incapable de me le rappeler. Mais j'espère que cet aveu me vaudra l'indulgence de tous ceux que cette omission aura fâcheusement surpris, à juste titre. 